\title{
Ventilatory Interaction between Oxygen and Carbon Dioxide in the Preterm Primate
}

\author{
ROBERT D. GUTHRIE, WILLIAM A. LAFRAMBOISE, THOMAS A. STANDAERT, \\ GERALD VAN BELLE, AND DAVID E. WOODRUM \\ Divisions of Neonatal Biology and Biostatistics, University of Washington School of Medicine, \\ Seattle, Washington
}

\begin{abstract}
The steady state ventilatory response to inhaled $\mathrm{CO}_{2}$ was measured in eleven unanesthetized premature Macaca nemestrina during the first 3 wk of life in different steady state background $\mathrm{O}_{2}$ mixtures hypoxia $\left(\mathrm{FIO}_{2}=0.08\right.$ or 0.12$)$, normoxia $\left(\mathrm{FIO}_{2}=0.21\right)$ and hyperoxia $\left(\mathrm{FrO}_{2}=0.96\right)$. Hyperoxic $\triangle \dot{V}_{1} / \triangle \mathbf{P A C O}_{2}$ and $\Delta \mathbf{P}_{0.2} /$ $\triangle \mathbf{P A C O}_{2}$ were significantly greater than hypoxic $\triangle \dot{\mathbf{V}}_{\mathrm{l}} /$ $\triangle \mathbf{P A C O}_{2}$ and $\triangle \mathbf{P}_{0.2} / \triangle \mathbf{P A C O}_{2}$, respectively, at both 2 and 21 days postnatal age by the Mann Whitney test of nonparametric ranking ( 2 days: 89.6 and $80.2^{\circ}$ versus 88.7 and $56.4^{\circ}$, respectively; 21 days: 89.3 and $76.6^{\circ}$ versus 50.2 and $57.1^{\circ}$, respectively; $\left.p<0.05\right)$. Hypoxic $\Delta \dot{V}_{\mathrm{I}} / \triangle \mathbf{P A C O}_{2}$ was significantly depressed compared to normoxic $\Delta \dot{V}_{\mathrm{l}}$ $\triangle \mathbf{P A C O}_{2}$ only at 21 days of age $\left(50.2\right.$ versus $89.4^{\circ}$, respectively; $p<0.05$ ); hyperoxic $\mathrm{CO}_{2}$ sensitivity and normoxic $\mathrm{CO}_{2}$ sensitivity did not differ at either age. The ventilatory interaction between $\mathrm{O}_{2}-\mathrm{CO}_{2}$ in the neonatal primate appears to be the inverse of the typical adult ventilatory interaction. It is hypothesized that differential changes in brain stem blood flow between neonates and adults might explain this difference in $\mathrm{O}_{2}-\mathrm{CO}_{2}$ ventilatory interaction. (Pediatr Res 19: 528-533, 1985)
\end{abstract}

\section{Abbreviations}

$V_{I}$, minute ventilation

$V_{\mathrm{T}}$, tidal volume

f, respiratory frequency

$\mathrm{PACO}_{2}$, arterial carbon dioxide tension

$\mathrm{V}_{\Upsilon} / \mathrm{T}_{\mathrm{i}}$, inspiratory flow

$\triangle \dot{V}_{\mathrm{l}} / \triangle \mathrm{PACO}_{2}$, ventilatory response to $\mathrm{CO}_{2}$ expressed as change in minute volume

$\triangle \mathbf{P}_{0.2} / \triangle \mathbf{P A C O}_{2}$, ventilatory response to $\mathrm{CO}_{2}$ expressed as change in airway occlusion pressures

$T_{i}$, inspiratory time

$T_{e}$, expiratory time

$T_{\text {tot }}$, respiratory cycle time

$T_{i} / T_{\text {tot }}$, inspiratory duty cycle

$\mathrm{T}_{\mathrm{icc}}$, inspiratory time after airway occlusion

FRC, functional residual capacity

$\mathrm{FIO}_{2}$, environmental oxygen concentration

NREM, nonrapid eye movement

An additive ventilatory interaction between hypoxia and hypercapnia is considered to be a normal characteristic of the

Received March 12, 1984; accepted January 25, 1985.

Reprint requests Dr. Robert D. Guthrie, Director of Neonatology, MageeWomens Hospital, Forbes Avenue and Halket Street, Pittsburgh, PA 15213.

Supported by Grants HL-19187, HD-10356, and RR-00166 from the National Institutes of Health. human adult respiratory control system. Moderate hypoxia augments the ventilatory response to carbon dioxide in the awake adult man $(1,2)$ whereas hyperoxia decreases the ventilatory response to inhaled $\mathrm{CO}_{2}$. More detailed studies in animals indicate that separate, interactive depressant and stimulant effects of hypoxia and carbon dioxide can coexist $(3,4)$. Therefore, the ventilatory interaction between oxygen and carbon dioxide in adult man and animals is a complex one involving the coexistence of stimulant and depressant interactions.

In contrast to this relatively detailed understanding of the interaction between oxygen and carbon dioxide in adult species, there is only one report in infants. Rigatto et al. (5) have shown that moderate hypoxia depresses $\mathrm{CO}_{2}$ sensitivity in premature human infants 2 to 11 days of age whereas hyperoxia augments the ventilatory response to inhaled $\mathrm{CO}_{2}$. This apparent contrast to the ventilatory interaction of $\mathrm{O}_{2}$ and $\mathrm{CO}_{2}$ in adults stimulated us to reexamine this question in more detail in the preterm monkey.

Since normoxic $\mathrm{CO}_{2}$ sensitivity has been reported to increase with advancing postnatal age (6) and since the infant's ventilatory response to hypoxia is known to change from an initial biphasic response to a mature, adult-like response of sustained hyperventilation by 18 to 21 days of age $(7,8)$, we hypothesized that $\mathrm{O}_{2-}$ $\mathrm{CO}_{2}$ interaction might become similar to that of adults during this time period.

\section{MATERIALS AND METHODS}

Eleven premature infant Macaca nemestrina at a gestational age of 150 to 153 days ( 0.89 to 0.91 of term) were obtained from timed conceptions by cesarean section. Birth weights ranged between 350 and $450 \mathrm{~g}$. Chest roentgenograms, blood gases, and clinical criteria confirmed the infants were healthy and free of lung disease. Eleven monkeys were studied at 2 days of age and nine at a postnatal age of 21 days including eight animals which were studied at both ages.

The animals were restrained in the supine position and warmed by a heating pad and an overhead radiant heat source to maintain a neutral thermal environment as determined by maintaining an abdominal surface to core temperature gradient at $\pm 0.5^{\circ} \mathrm{C}$ on day 2 and $\pm 1.0^{\circ} \mathrm{C}$ on day 21 . Group mean core temperature was the same on both study days at $37.5 \pm 0.5^{\circ} \mathrm{C}$. A flexible cannula was modified for use as a tracheostomy tube (flow resistance $=0.25 \mathrm{~cm} \mathrm{H} \mathrm{H}_{2} \mathrm{O} / \mathrm{liter} / \mathrm{min}$ at $3 \mathrm{liter} / \mathrm{min}$ ) and surgically placed under nitrous oxide plus local chloroprocaine $\mathrm{HCl}$ anesthesia on day 2 . The tracheostomy necessarily eliminated the potential influence of changes in the resistance of upper airways during breathing the various respiratory stimuli. An end expiratory pressure of $2 \mathrm{~cm} \mathrm{H}_{2} \mathrm{O}$ was applied via the tube to maintain the animal at FRC. After the study was completed, the tube was removed and tracheal incision closed. Replacement of the cannula (flow resistance $=0.10 \mathrm{~cm} \mathrm{H}_{2} \mathrm{O} / \mathrm{liter} / \mathrm{min}$ at 3 liter/ 
min) on day 21 required ketamine anesthesia $(5 \mathrm{mg} / \mathrm{kg}$ intramuscularly) to achieve sufficient sedation to perform the procedures. An arterial catheter was placed in the umbilical or femoral artery under local anesthesia. After completion of the preparatory surgery on both days of the study, the animals were allowed $2 \mathrm{~h}$ to recover from the general anesthesia by which time the effects of $\mathrm{N}_{2} \mathrm{O}$ are dissipated; no ketamine was detectable in the blood of these infants at this time (9).

All experimental trials were initiated during NREM sleep (quiet sleep). Electroencephalogram, electrooculogram, electromyogram from posterior neck muscles, and heart rate were obtained from disc electrodes and simultaneously recorded on a polygraph (Beckman Accutrace) as described in a previous study (6). Sleep state was scored according to standard criteria modified for infants (6). The younger animals remained in NREM sleep during the various respiratory stimuli as did the 3-wk-old animals during inhalation of the normoxic and hyperoxic gas mixtures. The older animals experienced short periods of arousal during inhalation of the hypoxic gas mixtures; data were collected only during quiet regular respirations.

Respiratory flow was detected by a hot wire anemometer as the infant added to (expiration) or subtracted from (inspiration) a constant background flow electrically balanced to an artificial zero (10). The area under the inspiratory flow tracing was integrated by a signal conditioner (Hewlett-Packard $8815 \mathrm{~A}$ ) to determine $V_{\mathrm{T}}$ in a range $(1 \pm 0.1$ to $10 \pm 0.2 \mathrm{ml})$ for which the instrument was calibrated prior to each trial. A pressure transducer (Gould P-50) monitored airway pressure through a sidearm of the tracheal tube. The flow, $\mathrm{V}_{\mathrm{T}}$, and airway pressure signals were displayed on an oscilloscope and a chart recorder.

Control ventilation was measured while the animal breathed room air during a 5 - to $10-\mathrm{min}$ period of NREM sleep prior to the study gas administration. During this period five tracheal occlusions were performed at end expiration and a control arterial blood gas sample was taken from the umbilical or femoral catheter $(0.5 \mathrm{ml}$ for analysis in Instrument Laboratories no. 713 Blood Gas Analyzer). After the room air control period, the animals were then administered during NREM sleep (via a separate stimulus gas circuit) 8 or $12 \% \mathrm{O}_{2}, 21 \% \mathrm{O}_{2}$, or $96 \% \mathrm{O}_{2}$ for 5 min-a time sufficient to obtain a steady state $(6,8)$ after which five occlusions of the airway at end expiration were performed allowing time between occlusions for ventilatory re- covery; an arterial blood gas sample was then taken. The hypoxic gas mixture was chosen to be 8 or $12 \%$ at the different postnatal ages to give an arterial $\mathrm{pO}_{2}$ during steady state hypoxia of approximately 20 to 25 Torr at each age. Minute volume did not change during hyperoxia; the ventilatory response to hypoxia alone has been published previously (7). Then $4 \% \mathrm{CO}_{2}$ plus the various separate concentrations of $\mathrm{O}_{2}$ were administered for 5 to 7 min during NREM sleep to achieve steady state ventilation after which five airway occlusions at random intervals were again performed; arterial blood gas tensions were determined and the experimental trial was terminated. After addition of $4 \% \mathrm{CO}_{2}$ to the hypoxic background gas mixtures, arterial oxygen tension increased to $40 \pm 0.5$ Torr at 2 days of age and $30.5 \pm 0.5$ Torr at $3 \mathrm{wk}$ of age during steady state hypoxic hypercapnia. Each stimulus gas was given two to four times to each animal at each age and $15 \mathrm{~min}$ were allowed for recovery between trials. All gas mixtures were administered at room temperature and saturated with water vapor. Only those data obtained in a trial that was not interrupted by a change in sleep state were accepted for analysis except during the hypoxic conditions in the 3-wk-old animals where microarousals occurred and data were collected during quiet regular breathing periods only.

Five breaths during quiet regular respiration preceding an occluded inspiratory effort were designated the control breath.s. $\dot{V}_{1}$ was calculated from the mean $V_{T}$ and frequency of the five control breaths in each baseline or stimulus trial. Timing components, ie, $T_{i}, T_{e}$, and $T_{\text {tot }}$ were measured in order to determine the effects of the stimulus gases on the $T_{i} / T_{\text {tor }}$ and $V_{T} / T_{i}$ (11). An estimate of changes in the central inspiratory setting was obtained by analyzing the changes in $\mathrm{T}_{\mathrm{i}_{\text {occ }}}$; this measure approximates but does not equal the bulbopontine inspiratory setting $(12,13)$. The airway pressures achieved at $200 \mathrm{~ms}\left(\mathrm{P}_{0.2}\right)$ of occluded inspiration provided an indirect measure of respiratory neuromuscular output $(4,14)$. All volume data were normalized for body weight and expressed in milliliters per kilogram. A representative tracing during hypoxic $\mathrm{CO}_{2}$ breathing is shown in Figure 1.

The slopes of the ventilatory responses to inhaled $\mathrm{CO}_{2}$ were calculated from the steady state point on each $\mathrm{O}_{2}$ mixture to the steady state point of the various $\mathrm{O}_{2}$ mixtures plus $4 \% \mathrm{CO}_{2}(6,8)$. The ventilatory response to inhaled $\mathrm{CO}_{2}$ was expressed both as $\triangle \dot{\mathrm{V}}_{\mathrm{I}} / \triangle \mathrm{PACO}_{2}$ and $\left(\triangle \mathrm{P}_{0.2} / \triangle \mathrm{PACO}_{2}\right)$. Because several of the hyper-

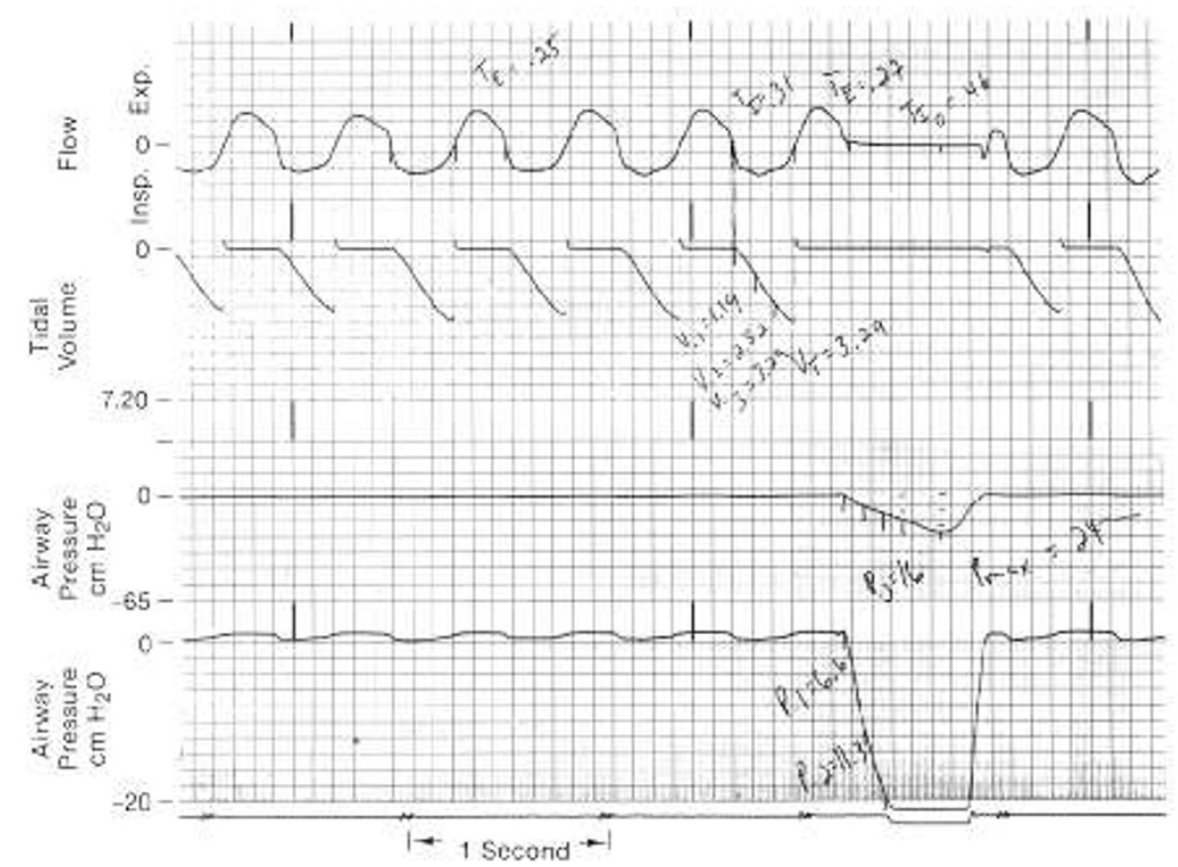

Fig. 1. A representative polygraph tracing during inhalation of an hypoxic $\mathrm{CO}_{2}$ gas mixture is shown demonstrating the changes in airway flow, $\mathrm{V}_{\mathrm{T}}$, and airway occlusion pressures. 
oxic hypercapnic ventilatory slopes approached or reached infinity, all slopes were converted to angular coordinates according to the formula:arc $\tan \left(\triangle \dot{\mathrm{V}}_{1} / \triangle \mathrm{PACO}_{2}\right)=\theta$ or arc $\tan \left(\triangle \mathrm{P}_{0.2} /\right.$ $\left.\triangle \mathrm{PACO}_{2}\right)=\theta$ were $\theta$ equals the slope of the ventilatory response to $\mathrm{CO}_{2}$ expressed in degrees. This statistical analysis is a simplification of the mean directional analysis technique suggested by Daubenspeck and Ogden (15).

The anuglar slopes were analyzed using the Mann Whitney test (two-tailed) of nonparametric ranking for unpaired numbers (16). This test is more appropriate than the Student's $t$ test in this situation as the calculated angles are not normally distributed. The changes in the timing and volumetric components of ventilation were analyzed using the Student's $t$ test (two-tailed) for paired variables in the eight animals studied at both postnatal ages. For statistical comparison, the change in a given variable between the steady state point in hyperoxia, normoxia, or hypoxia was compared to the respective variable in the same background $\mathrm{O}_{2}$ mixture 5 to $7 \mathrm{~min}$ after $\mathrm{CO}_{2}$ had been added to the background gas and a steady state had been reached $(6-8)$. All $p$ values equal to or less than 0.05 were considered significant.

\section{RESULTS}

Volumetric, pressure, and timing data. There was a highly significant increase in $V_{\Upsilon}$ and $V_{T} / T_{i}$ when $4 \% C O_{2}$ was added to each of the background $\mathrm{O}_{2}$ mixtures $(p<0.01)$ except during inhalation of the hypoxic gas at $3 \mathrm{wk}$ of age when the increases in both variables approached but did not reach statistical significance because of increased variability in $\mathrm{V}_{\mathrm{T}}(p<0.1)$ (Fig. $2 \mathrm{~A}$ and $B$ ). Airway occlusion pressures increased significantly during normoxic hypercapnia and hyperoxic hypercapnia at both ages $(p<0.01)$ and during hypoxic hypercapnia at 2 days of age $(p$ $<0.01$ ) (see fig. 3); however, the change in $\mathrm{P}_{0.2}$ from after $5 \mathrm{~min}$
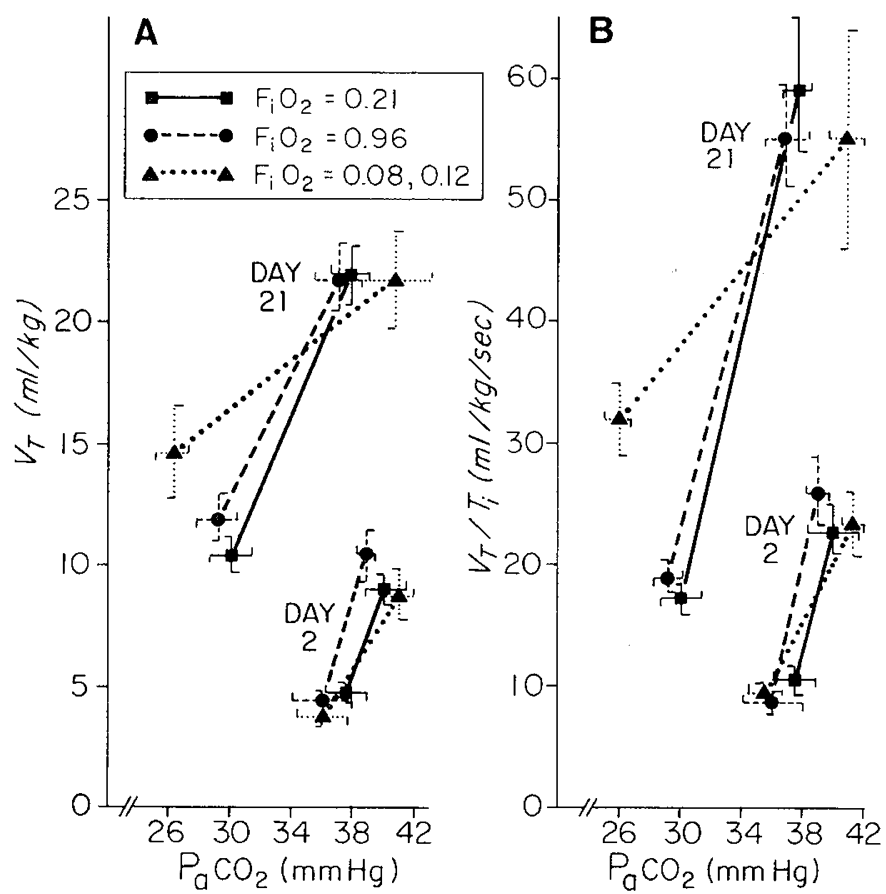

Fig. 2. $A, \mathrm{~V}_{\mathrm{T}}$ per kilogram is plotted as a function of arterial carbon dioxide tensions at postnatal ages of 2 and 21 days. Data are expressed as means $\pm \mathrm{SE}$ and the figure legend for the different background $\mathrm{O}_{2}$ mixtures is as shown. $\mathrm{V}_{\mathrm{T}}$ increased significantly $(p<0.01)$ during $\mathrm{CO}_{2}$ inhalation in each background $\mathrm{O}_{2}$ mixture except during hypoxic hypercapnia at 21 days of age. $B$, "inspiratory drive" $\left(\mathrm{V}_{\mathrm{T}} / \mathrm{T}_{\mathrm{i}}\right)$ is plotted as a function of arterial carbon dioxide tensions. Data are expressed as mean $\pm \mathrm{SE}$. Figure legends are the same as $A . \mathrm{V}_{\mathrm{T}} / \mathrm{T}_{\mathrm{i}}$ increased significantly ( $p$ $<0.01$ ) in each of the experimental conditions except during hypoxic hypercapnia at 21 days of age.

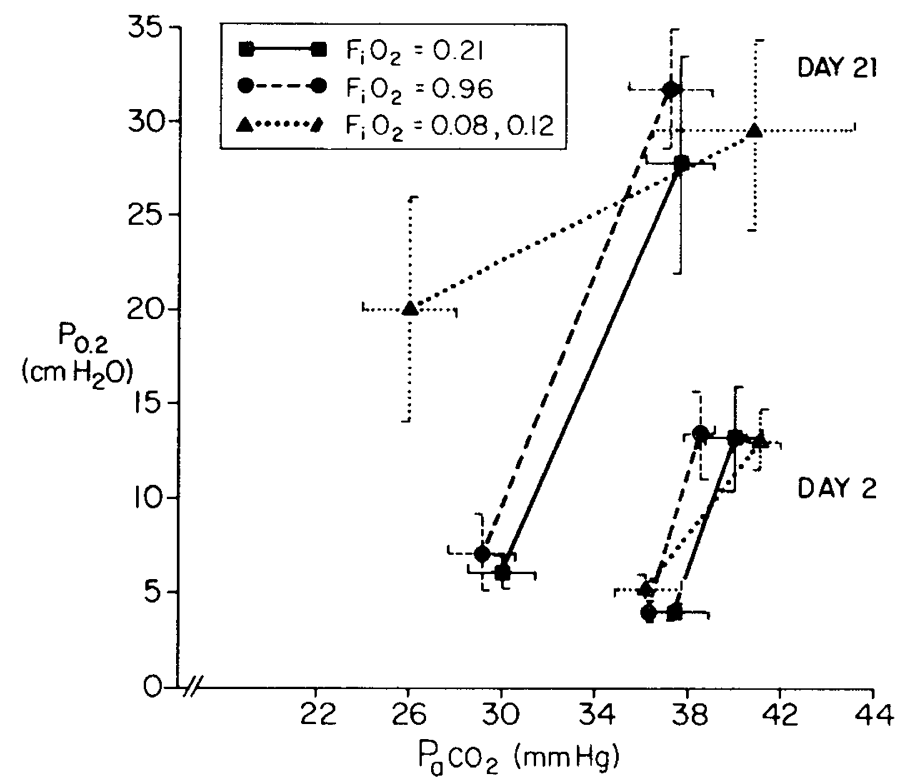

Fig. 3. Airway occlusion pressures at $200 \mathrm{~ms}\left(\mathrm{P}_{0.2}\right)$ is plotted as a function of arterial carbon dioxide tensions at postnatal ages of 2 and 21 days. Data are expressed as means $\pm \mathrm{SE}$ and the figure legend for the different background oxygen mixtures is as shown. Hyperoxic $\triangle \mathrm{P}_{0.2} /$ $\triangle \mathrm{PACO}_{2}$ differed from hypoxic $\triangle \mathrm{P}_{0.2} / \triangle \mathrm{PACO}_{2}$ at 2 and 21 days of age by the Mann Whitney test $(p<0.05)$.
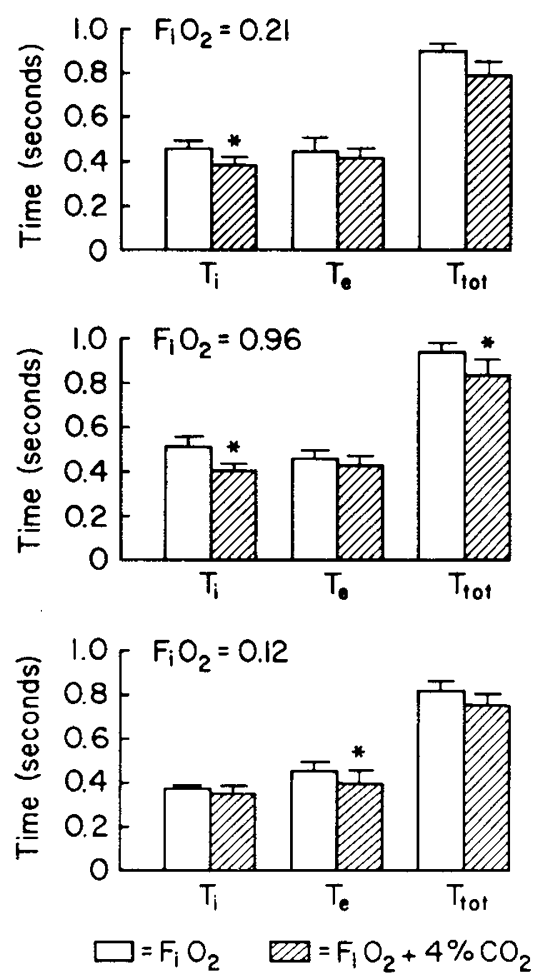

Fig. 4. Changes in the timimg components of ventilation in 2-dayold animals following addition of $4 \% \mathrm{CO}_{2}$ to the different background $\mathrm{O}_{2}$ mixtures are shown as means $\pm \mathrm{SE}$. Open bars are steady state data in the specified background $\mathrm{O}_{2}$ mixtures and slashed bars are changes after addition of $4 \% \mathrm{CO}_{2}$ to the background mixture. Asterisk denotes significant change from the value in the respective steady state $\mathrm{O}_{2}$ mixture at $p<0.05$ or better.

of hypoxia to hypoxic hypercapnia was not significant at 21 days of age $(p<0.2)$.

In the animals studied at 2 days of age, respiratory frequency increased and $T_{\text {tot }}$ decreased only between steady state hyperoxia 
and hyperoxic hypercapnia $(p<0.05)$ (Fig. 4). There were no differences in frequency between normoxic hypercapnia and hypoxic hypercapnia and the respective $\mathrm{O}_{2}$ steady state points indicating that the increase in $\dot{V}_{1}$ during $\mathrm{CO}_{2}$ inhalation in these background $\mathrm{O}_{2}$ mixtures was mediated by an increase in $\mathrm{V}_{\mathrm{T}}$ alone at this age. Inspiratory time was shortened during normoxic hypercapnia and hyperoxic hypercapnia compared to the respective steady state conditions but the ratio of $T_{i} / T_{\text {tot }}$ was unchanged. $\mathrm{T}_{\mathrm{i}_{\infty}}$ did not change during any of the experimental conditions in the younger animals (Table 1 ).

Table 1. Changes in $T_{i_{\text {occ }}}$ after airway occlusion*

\begin{tabular}{lcc}
\hline & \multicolumn{2}{c}{ Postnatal age } \\
\cline { 2 - 3 } Experimental trial & 2 days & 21 days \\
\hline $\begin{array}{l}\text { Hyperoxia } \\
\text { Hyperoxic hypercap- }\end{array}$ & $0.72 \pm 0.22$ & $0.83 \pm 0.26$ \\
nia & & \\
& & \\
Normoxia & $0.67 \pm 0.40$ & $0.10 \dagger$ \\
Normoxic hypercap- & $0.58 \pm 0.19$ & $0.73 \pm 0.12$ \\
nia & & \\
& & \\
Hypoxia & $0.68 \pm 0.39$ & $0.52 \pm 0.08 \ddagger$ \\
Hypoxic hypercapnia & $0.58 \pm 0.19$ & $0.44 \pm 0.08 \ddagger$ \\
\hline
\end{tabular}

* Values shown are mean $\pm 1 \mathrm{SD}$ for $\mathrm{T}_{\mathrm{i}_{\text {occ }}}$ in the different experimental conditions.

$\dagger$ Difference from respective steady state background $\mathrm{O}_{2}$ mixture at $p$ $<0.05$ or better.

$\ddagger$ Significant difference at $p<0.01$ from corresponding room air value at $3 \mathrm{wk}$ of age.
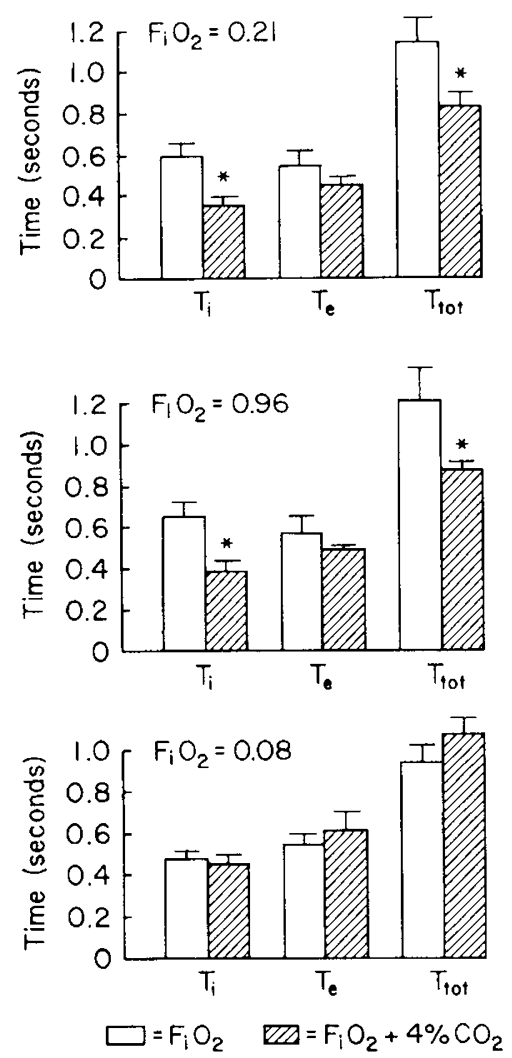

Fig. 5. Changes in the timing components of ventilation in 3-wk-old animals following addition of $4 \% \mathrm{CO}_{2}$ to the specified background $\mathrm{O}_{2}$ mixtures. Legends are as in Figure 4. Asterisk denotes significant differences from the data in the respective steady state $\mathrm{O}_{2}$ mixture at $p<0.01$ or better.

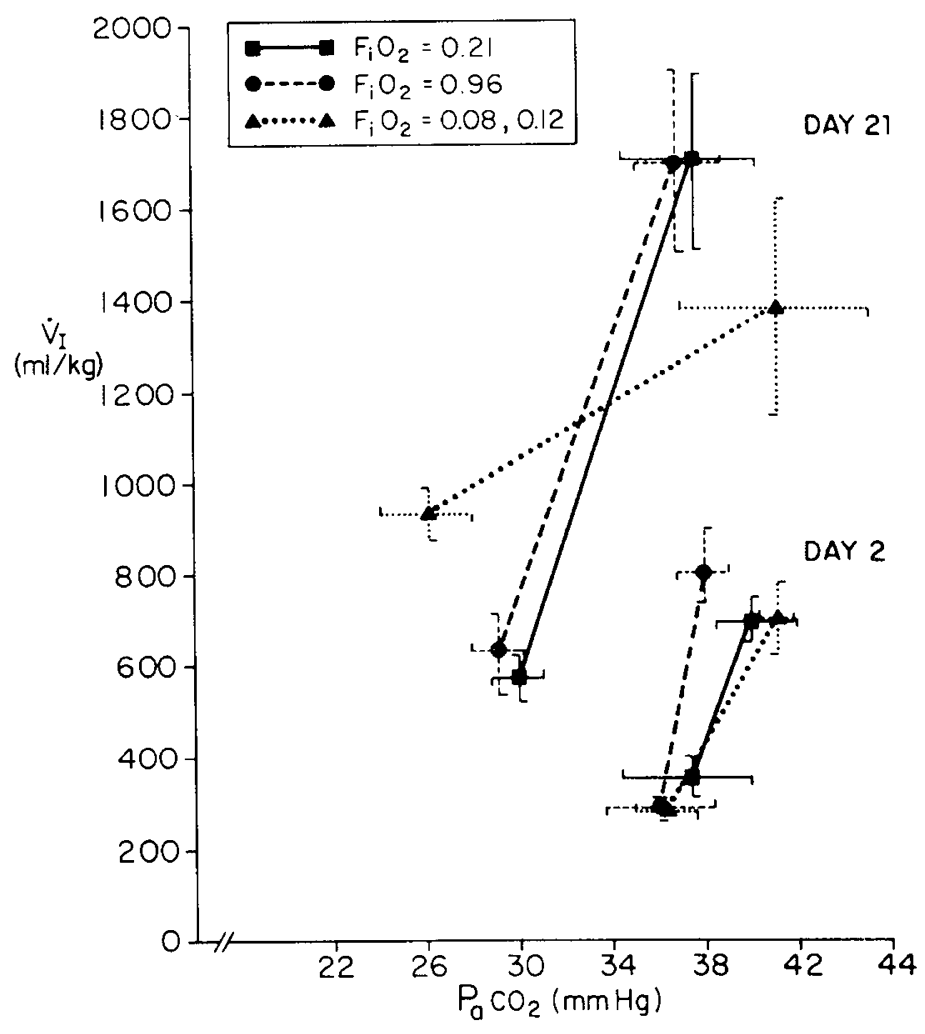

Fig. 6. Minute volume per kilogram is plotted against arterial carbon dioxide tension at postnatal ages of 2 and 21 days. The code for different background $\mathrm{O}_{2}$ mixtures is as shown in the figure. Data are means $\pm \mathrm{SE}$. Hyperoxic $\mathrm{CO}_{2}$ sensitivity was significantly greater than hypoxic $\mathrm{CO}_{2}$ sensitivity at both 2 and 21 days of age by the Mann Whitney test at $p$ $<0.05$. Hypoxic $\mathrm{CO}_{2}$ sensitivity was significantly lower than normoxic $\mathrm{CO}_{2}$ sensitivity at 21 days of age only $(p<0.05)$.

In the 3-wk-old animals, respiratory frequency increased significantly and $T_{\text {tot }}$ decreased during hyperoxic and normoxic hypercapnia $(p<0.01)$ (Fig. 5). A concomitant shortening of $T_{i}$ in these conditions $(p<0.01)$ was greater than the decrease in $\mathrm{T}_{\text {tot }}$ such that $\mathrm{T}_{\mathrm{i}} / \mathrm{T}_{\text {tot }}$ also decreased significantly (normoxia to normoxic hypercapnia $0.52 \pm 0.01$ to $0.45 \pm 0.02$, respectively; hyperoxia to hyperoxic hypercapnia $0.53 \pm 0.01$ to $0.45 \pm 0.01$, respectively; $p<0.01$ ). This increase in respiratory frequency and the shortening of $T_{i}$ and $T_{i} / T_{\text {tot }}$ during hyperoxic and normoxic hypercapnia was associated with a shortening of $\mathrm{T}_{\mathrm{i}_{\mathrm{oco}}}$ suggesting that the central inspiratory setting also decreased. None of the timing variables changed during hypoxic hypercapnia compared to steady state hypoxia alone, although frequency was increased during hypoxia (7).

Ventilatory response to inhaled $\mathrm{CO}_{2}$. The angular slope of the steady state $\mathrm{CO}_{2}$ response when expressed as the change in $\dot{V}_{\mathrm{l}} /$ $\mathrm{kg}$ per unit change in $\mathrm{PACO}_{2}$ was significantly greater during inhalation of the hyperoxic background mixture than during inhalation of the hypoxic background gas at both 2 and 21 days of age (Table 2 and Fig. 6). The angular slope of the ventilatory response to $\mathrm{CO}_{2}$ during hypoxia was significantly depressed compared to the angular slope during normoxia at 21 days of age but in the 2-day-old animals the responses did not differ. Hyperoxia did not significantly augment the angular slope of the $\mathrm{CO}_{2}$ response curve compared to normoxia at either postnatal age.

When the increases in airway occlusion pressures per unit increase in $\mathrm{PACO}_{2}$ were utilized as an index of the $\mathrm{CO}_{2}$ response, the angular slope during hypoxia was again significantly depressed compared to the hyperoxic $\mathrm{CO}_{2}$ response at both 2 and 21 days of age by the Mann Whitney rank test (Table 2 and Fig. 
Table 2. Angular slopes of the $\mathrm{CO}_{2}$ response in different background $\mathrm{O}_{2}$ mixtures*

\begin{tabular}{|c|c|c|c|c|}
\hline $\begin{array}{l}\text { Postnatal } \\
\text { age } \\
\text { (days) }\end{array}$ & Background gas: & Hypoxia & Normoxia & Hyperoxia \\
\hline 2 & $\begin{array}{l}\arctan \Delta \dot{\mathrm{V}}_{\mathrm{I}} / \triangle \mathrm{P}_{\mathrm{ACO}_{2}} \\
\arctan \Delta \mathrm{P}_{0.2} / \Delta \mathrm{PACO}_{2}\end{array}$ & $\begin{array}{c}88.97^{\circ} \\
\left(85.91^{\circ} \rightarrow 90.0^{\circ}\right) \\
56.43^{\circ} \\
\left(-18.4^{\circ} \rightarrow 90.0^{\circ}\right)\end{array}$ & $\begin{array}{c}89.47^{\circ} \\
\left(88.84^{\circ} \rightarrow 90.25^{\circ}\right) \\
70.59^{\circ} \\
\left(47.98^{\circ} \rightarrow 103.9^{\circ}\right)\end{array}$ & $\begin{array}{c}89.63^{\circ} \dagger \\
\left(88.17^{\circ} \rightarrow 91.02^{\circ}\right) \\
80.23^{\circ} \dagger \\
\left(46.94^{\circ} \rightarrow 150.3^{\circ}\right)\end{array}$ \\
\hline 21 & $\begin{array}{l}\arctan \Delta \dot{\mathrm{V}}_{\mathrm{i}} / \Delta \mathrm{P}_{\mathrm{ACO}_{2}} \\
\arctan \Delta \mathrm{P}_{0.2} / \Delta \mathrm{PACO}_{2}\end{array}$ & $\begin{array}{c}50.18^{\circ} \\
\left(-5.30^{\circ} \rightarrow 89.73^{\circ}\right) \\
57.11^{\circ} \\
\left(-57.2^{\circ} \rightarrow 85.0^{\circ}\right)\end{array}$ & $\begin{array}{c}89.37^{\circ} \ddagger \\
\left(88.16^{\circ} \rightarrow 90.28^{\circ}\right) \\
72.90^{\circ} \\
\left(45.57^{\circ} \rightarrow 119.33^{\circ}\right)\end{array}$ & $\begin{array}{c}89.33 \dagger \\
\left(87.4^{\circ} \rightarrow 90.0^{\circ}\right) \\
76.60^{\circ} \dagger \\
\left(70.3^{\circ} \rightarrow 88.0^{\circ}\right)\end{array}$ \\
\hline
\end{tabular}

* Data are mean angular slopes in degrees with the ranges in parentheses.

$\dagger$ Significant difference between angular slopes in hyperoxia compared to angular slopes determined in hypoxia by the Mann Whitney nonparametric rank test $(p<0.05)$ at corresponding ages.

$\ddagger$ Significant difference compared to hypoxic $\mathrm{CO}_{2}$ response at 21 days of age at $p<0.05$.

3). The angular slope of the hypoxic $\mathrm{CO}_{2}$ response was not different from the normoxic $\mathrm{CO}_{2}$ response at either age and the hyperoxic $\mathrm{CO}_{2}$ response was not significantly augmented compared to normoxic $\mathrm{CO}_{2}$ response values.

Postnatal maturation did not influence steady state $\Delta \dot{\mathrm{V}}_{\mathrm{I}} /$ $\triangle \mathrm{PACO}_{2}$ or $\triangle \mathrm{P}_{0.2} / \triangle \mathrm{PACO}_{2}$ in NREM sleep during normoxia, hyperoxia, or hypoxia in this study (Table 2). Hypoxic $\mathrm{CO}_{2}$ sensitivity did not convert from depression to an adult-like augmentation compared to the slope determined in a normoxic or hyperoxic background gas mixture by $3 \mathrm{wk}$ of age; in fact, the hypoxic $\triangle \dot{\mathrm{V}}_{1} / \triangle \mathrm{PACO}_{2}$ at $3 \mathrm{wk}$ of age actually tended to be lower than the hypoxic $\mathrm{CO}_{2}$ response at a postnatal age of 2 days but this difference did not reach statistical significance $(p<0.1)$.

\section{DISCUSSION}

These results confirm in the preterm primate the previous observations in human prematures that the ventilatory response to inhaled $\mathrm{CO}_{2}$ is increased during hyperoxia compared to a relative depression during hypoxia (5). The data extend previous observations by controlling for the potential effects of sleep state and by demonstrating that hypoxia continues to depress the $\mathrm{CO}_{2}$ response in newborns older than previously studied-at an age when the ventilatory response to hypoxia alone is known to be adult-like, ie, sustained hyperventilation (7). In addition, the volumetric and timing components of the augmented $\mathrm{CO}_{2}$ response during hyperoxia and its depression during hypoxia are defined for the first time. The increase in the ventilatory response to $\mathrm{CO}_{2}$ observed during inhalation of the hyperoxic background gas was mediated by a significant increase in $\mathrm{V}_{\mathrm{T}}$ and a decrease in $T_{i}$ and $T_{\text {tot }}$ at both postnatal ages studied. The augmentation of respiratory frequency in the 3-wk-old animals appeared to be centrally mediated as has been shown in adult cats (13); whereas, in the younger animals, the means by which frequency increased was not identified in the present investigation although others have found this response to be vagally mediated (17). Since the tracheostomy eliminated the role of the upper airway muscles in altering the $\mathrm{V}_{\mathrm{T}}$ and frequency response to the stimuli, the components and magnitude of the ventilatory response, especially changes in $\mathrm{T}_{\mathrm{e}}$ might be different in an intact animal.

The relative depression of the $\mathrm{CO}_{2}$ response during hypoxic conditions was determined in the younger animals by a failure of respiratory frequency to increase further above the level already elevated during steady state hypoxia (7). In the 3-wk-old animals, $V_{\mathrm{T}}$ and frequency were already increased during steady state hypoxia and both did not further increase significantly after the addition of $\mathrm{CO}_{2}$ to the inspired gas mixture. These two factors and the associated larger increase in $\mathrm{PACO}_{2}$ resulted in the observed depression of $\triangle \dot{\mathrm{V}}_{\mathrm{I}} / \triangle \mathrm{PACO}_{2}$ during hypoxic conditions compared to hyperoxic conditions. Changes in $\mathrm{O}_{2}$ consumption among the experimental conditions cannot be ruled out in the present study but others have found no change in the newborn's $\mathrm{O}_{2}$ consumption during hypoxia under conditions of neutral thermal environment (18).

The observed ventilatory interactions between $\mathrm{O}_{2}$ and $\mathrm{CO}_{2}$ in this study and the previous investigation in human prematures by Rigatto et al. (5) contrast with the usual findings in adults of hypoxic-induced augmentation of the $\mathrm{CO}_{2}$ response and a decrease of the slope of the $\mathrm{CO}_{2}$ response during hyperoxia $(1,2)$.

The mechanism(s) involved in the apparently contrasting ventilatory interactions between oxygen and carbon dioxide in infants and adults is (are) unclear. Differential effects of $\mathrm{O}_{2}$ and $\mathrm{CO}_{2}$ on the sensor, integrator, and/or effective elements of the respiratory control system might be involved. Differences in experimental design might also be important as the two studies in the newborn employed the steady state method whereas the rebreathing method was utilized in the classic adult studies (1, 2).

Differences in input from peripheral chemoreceptors and the consequent changes in phrenic nerve activity do not appear to be important since the immediate $(<1 \mathrm{~min})$ ventilatory effects of hypoxia and hyperoxia are the same in infants and adults when the alveolar $\mathrm{PO}_{2}$ levels are similar (19) and carotid sinus nerve activity remains active during hypoxia (20). However, quantitative data on increased carotid sinus and phrenic nerve activity during hypoxia and hyperoxia at a constant $\mathrm{PCO}_{2}$ are not available in the newborn to compare to adult data.

Differences in the levels of stimuli $\left[(\mathrm{H})^{+}\right.$and/or $\left.\mathrm{PCO}_{2}\right]$ presenting to the central chemoreceptors might explain the opposite ventilatory interaction between $\mathrm{O}_{2}$ and $\mathrm{CO}_{2}$ in infants and adults. Hyperoxia, hypoxia, and hypercapnia induce changes in cerebral blood flow which are of a different magnitude in newborns compared to adults (21-24); this difference might alter the magnitude of the stimuli at central chemoreceptors (25). Hyperoxia decreases cerebral blood flow more in newborn than adult animals $(21,22)$ and hypercapnia increases cerebral flow less in the newborn than in the adult monkey (24). Theoretically, a net decrease in brain stem blood flow during hyperoxic hypercapnia in the newborn but not the adult might result in a local increase in $(\mathrm{H})^{+}$and/or $\mathrm{PCO}_{2}$ surrounding central chemoreceptors and result in augmentation of $\triangle \dot{V}_{\mathrm{I}} / \triangle \mathrm{PACO}_{2}$. Such an augmentation of $\triangle \dot{V}_{\mathrm{I}} / \triangle \mathrm{PACO}_{2}$ has been demonstrated in the unanesthetized adult goat at a $30 \%$ reduction in brain blood flow (25).

Similarly, hypoxia is a more powerful stimulant to cerebral blood flow in neonates than in adult animals (23) and this increase in cerebral blood flow is blunted by hypocapnia more in adult than newborn monkeys (24). The resulting increase in medullary blood flow may be greater in the newborn than in adults and result in a diminution in the hypoxic hypercapnic ventilatory response; such an interaction has been demonstrated 
in adult dogs by perfusions of the vertebral artery with hypocapnic blood at increased flow rates during systemic hypercapnia (26). These hypotheses to explain the observed differences in $\mathrm{O}_{2-}$ $\mathrm{CO}_{2}$ ventilatory interaction between infants and adults remain to be tested by direct measures of brain stem blood flow, medullary $\mathrm{pH}$, and carotid sinus and phrenic nerve output during these experimental conditions.

Lastly, differential changes in the effectors of the respiratory control system might explain some of the apparent discrepancies in $\mathrm{O}_{2}-\mathrm{CO}_{2}$ interaction between neonates and adults. Different hypoxic- and hypercapnic-induced changes in FRC in newborns and adults might be relevant as it is known that changes in FRC influence the airway occlusion pressure generated by a constant phrenic nerve stimulation (27). The reported effects of hypoxia and hypercapnia on FRC in adults are inconsistent showing either small increases in FRC (28) or no changes (29). No data are available on the effects of $\mathrm{O}_{2}-\mathrm{CO}_{2}$ interaction on FRC and $\mathrm{P}_{0,2}$ in the newborn. Finally, hypoxia might induce diaphragmatic fatigue more in newborn than adult animals. Such an effect in adult men breathing $13 \% \mathrm{O}_{2}$ has been shown (30) but other studies show no effect of hypoxia on diaphragmatic fatigue in adults (31) or newborn kittens (20).

\section{REFERENCES}

1. Lloyd BB, Jukes MGM, Cunningham DJC 1957 The relation between alveolar oxygen pressure and the respiratory response to carbon dioxide in man. $\mathrm{Q} J$ Exp Physiol 43:214-227

2. Nielsen M, Smith H 1951 Studies on the regulation of respiration in acute hypoxia. Acta Physiol Scand 24:243-313

3. Cherniack NS, Edelman NH, Lahiri S 1970/71 Hypoxia and hypercapnia as respiratory stimulants and depressants. Respir Physiol 11:113-126

4. Ou LC, Miller MJ, Tenney SM 1976 Hypoxia and carbon dioxide as separate and interactive depressants of ventilation. Respir Physiol 28:347-358

5. Rigatto H. De La Torre Verduzco R, Cates DB 1975 Effects of $\mathrm{O}_{2}$ on the ventilatory response to $\mathrm{CO}_{2}$ in preterm infants. J Appl Physiol 39:896-899

6. Guthrie RD. Standaert TA, Hodson WA, Woodrum DE 1980 Sleep and maturation of eucapnic ventilation and $\mathrm{CO}_{2}$ sensitivity in the premature primate. J Appl Physiol 48:347-354

7. LaFramboisc WA, Standaert TA, Woodrum DE, Guthrie RD 1981 Occlusion pressures during the ventilatory response to hypoxemia in the newbor monkey. J Appl Physiol 51:1169-1174

8. Woodrum DE, Standaert TA, Mayock DE, Guthrie RD 1981 Hypoxic ventilatory response in the newbown monkey. Pediatr Res 15:367-370

9. Hargrove JC, Heavner JE, Guthrie RD, Morton WR 1980 Age dependent ketamine pharmacodynamics in the pigtail monkey (Macaca nemestrina). Proc West Pharmacol Soc 23:129-133

10. Godal A, Belenky DA, Standaert TA, Woodrum DE, Grimsrud L, Hodson
WA 1976 Application of the hot-wire anemometer to respiratory measurements in small animals. J Appl Physiol 40:275-277

11. Milic-Emili J, Grunstein M 1976 Drive and timing components of ventilation. Chest 70(suppl): 131-133

12. Grunstein MM, Younes M, Milic-Emili J 1973 Control of tidal volume and respiratory frequency in anesthetized cats. J Appl Physiol 35:463-476

13. Miserocchi G, Milic-Emili J 1975 Contribution of hypercapnic stimuli and of vagal afferents to the timing of breathing in anesthetized cats. Respir Physio 25:71-88

14. Yoshida A, Hayashi F, Sasaki K, Masuda Y, Honda Y 1981 Analysis of pressure profile in the occluded airway obtained at the beginning of inspiration in steady state hypercapnia. Am Rev Respir Dis 124:252-256

15. Daubenspeck JA, Ogden RD 1978 Estimation of response slopes in respiratory control using directional statistics. J Appl Physiol 45:823-829

16. Snedecor GW, Cochran WG 1967 Statistical Methods, 6th ed. The Jowa State University Press, Ames, IA

17. Marsland DW, Callahan BJ, Shannon DC 1975 The afferent vagus and regulation of breathing in response to inhaled $\mathrm{CO}_{2}$ in awake newborn lambs. Biol Neonate 27:102-107

18. Oliver TK, Karlberg P 1963 Gaseous metabolism in newly born human infants Am J Dis Child 105:427-435

19. Sankaran K, Wiebe H, Seshia M, Boychuk R, Cates D, Rigatto H 1979 Immediate and late ventilatory response to high and low $\mathrm{O}_{2}$ in preterm infants and adult subjects. Pediatr Res 13:875-878

20. Blanco CE, Hanson MA, Johnson P, Rigatto H 1984 Breathing pattern of kittens during hypoxia. J Appl Physiol 56:12-17

21. Harper AM 1972 Control of the cerebral circulation. In: Critchley M, O'Leary J, Jennett B (eds) Scientific Foundations of Neurology. Heinemann, London, pp 235-243

22. Kennedy C, Grave GD, Jehle JW 1971 Effect of hyperoxia on the cerebral circulation of the newborn puppy. Pediatr Res 5:659-667

23. Koehler RC, Jones MD Jr, Traystman RJ 1982 Comparison of cerebrovascular response to hypoxia in newborn and adult sheep. Fed Proc 41:7350A

24. Reivich M, Brann AW Jr, Shapiro H, Rawson J, Sano N 1971/72 Reactivity of cerebral vessels to $\mathrm{CO}_{2}$ in the newborn rhesus monkey. In: Cerebral Blood Flow and Intracranial Pressure. Proceedings of the 5th International Sym posium, Roma-Siena, Part I. Eur Neurol 6:132-136

25. Chapman RW, Santiago TV, Edelman NH 1979 Effects of graded reduction of brain blood flow on chemical control of breathing. J Appl Physiol 47:1289-1294

26. Feustel PJ, Adams JM, Donnelly DF, Dutton RE 1981 Ventilatory responses to hypocapnic vertebral artery perfusion in intact and carotid body denervated dogs. Respir Physiol 45:97-110

27. Eldridge F, Vaughn, K 1977 Relationship of thoracic volume and airway occlusion pressure: Muscular effects. J Appl Physiol 43:312-321

28. Garfinkel F, Fitzgerald RS 1978 The effect of hyperoxia, hypoxia and hypecapnia on FRC and occlusion pressure in human subjects. Respir Physiol 33:241-250

29. Scheene RB, Pierson DJ, Butler J 1981 Constancy of functional residual capacity in the supine position during hypoxia and hyperoxic hypercapnia. Am Rev Respir Dis 124:508-510

30. Roussos CS, Macklem PT 1977 Diaphragmatic fatigue in man. J Appl Physiol 43:189-197

31. Tenney SM, Reese RE 1968 The ability to sustain great breathing efforts. Respir Physiol 5:187-201 